\title{
The study of hormonal metabolism of Trincadeira and Syrah cultivars indicates new roles of salicylic acid, jasmonates, ABA and IAA during grape ripening and upon infection with Botrytis cinerea
}

\author{
João Coelho $^{\mathrm{a}}$, Marilia Almeida-Trapp ${ }^{\mathrm{b}}$, Diana Pimentel ${ }^{\mathrm{a}}$, Flávio Soares ${ }^{\mathrm{a}}$, Pedro Reis ${ }^{\mathrm{c}}$, \\ Cecília Rego ${ }^{c}$, Axel Mithöfer ${ }^{\mathrm{b}}$, Ana Margarida Fortes ${ }^{\mathrm{a}, *}$ \\ ${ }^{a}$ Universidade de Lisboa, Faculdade de Ciências de Lisboa, BioISI, Campo Grande, 1749-016, Lisboa, Portugal \\ ${ }^{\mathrm{b}}$ Research Group Plant Defense Physiology, Max Planck Institute for Chemical Ecology, 07745, Jena, Germany \\ ${ }^{\mathrm{c}}$ Instituto Superior de Agronomia, Universidade de Lisboa, Tapada da Ajuda, 1349-017, Lisboa, Portugal
}

\section{A R T I C L E I N F O}

\section{Keywords:}

Botrytis cinerea

Grape

Phytohormones

Necrotrophic pathogen

Plant resistance

Vitis vinifera

\begin{abstract}
A B S T R A C T
Hormones play an important role in fruit ripening and in response to biotic stress. Nevertheless, analyses of hormonal profiling during plant development and defense are scarce. In this work, changes in hormonal metabolism in grapevine (Vitis vinifera) were compared between a susceptible (Trincadeira) and a tolerant (Syrah) variety during grape ripening and upon infection with Botrytis cinerea. Infection of grapes with the necrotrophic pathogen Botrytis cinerea leads to significant economic losses worldwide.

Peppercorn-sized fruits were infected in the field and mock-treated and infected berries were collected at green, veraison and harvest stages for hormone analysis and targeted qPCR analysis of genes involved in hormonal metabolism and signaling. Results indicate a substantial reprogramming of hormonal metabolism during grape ripening and in response to fungal attack. Syrah and Trincadeira presented differences in the metabolism of abscisic acid (ABA), indole-3-acetic acid (IAA) and jasmonates during grape ripening that may be connected to fruit quality. On the other hand, high basal levels of salicylic acid (SA), jasmonates and IAA at an early stage of ripening, together with activated SA, jasmonates and IAA signaling, likely enable a fast defense response leading to grape resistance/ tolerance towards $B$. cinerea.

The balance among the different phytohormones seems to depend on the ripening stage and on the intraspecific genetic background and may be fundamental in providing resistance or susceptibility. In addition, this study indicated the involvement of SA and IAA in defense against necrotrophic pathogens and gains insights into possible strategies for conventional breeding and/or gene editing aiming at improving grape quality and grape resistance against Botrytis cinerea.
\end{abstract}

\section{Introduction}

Hormones play a key role in the development and ripening of grapes and other fleshy fruits as well as in biotic stress response [1,2]. Grape ripening involves important physiological shifts including cell wall remodeling, accumulation of soluble sugars, aroma compounds and anthocyanins, decline of inducible host defense responses, among others. Most of these changes are thought to be regulated by a complex interplay of hormonal signals involving ethylene, $\mathrm{ABA}$, brassinosteroids, jasmonates, polyamines, cytokinins and auxins [1,3]. Interestingly, similar phytohormones are regulated in the host in response to pathogens, and this regulation is modulated during fruit ripening when fruits show increased susceptibility to pathogens due to sugar accumulation
$[2,4]$.

Fleshy fruits can be classified into two groups, climacteric and nonclimacteric. Climacteric fruits such as tomato present an increase in respiration and ethylene biosynthesis upon initiation of ripening. In non-climacteric fruits such as grapes the respiratory burst and rise in ethylene production are absent at the onset of ripening (reviewed by Fortes et al. [1]). No single master switch controlling ripening initiation, such as ethylene in climacteric fruits, has yet been identified for non-climacteric fruits [5].

Abscisic acid (ABA), brassinosteroids (BRs), and ethylene have been suggested to promote ripening, while auxin delays some ripening associated processes and also interacts with other phytohormones such as $\mathrm{ABA}$ and ethylene [6]. In particular, in non-climacteric grape fruits ABA

\footnotetext{
* Corresponding author.

E-mail address: amfortes@fc.ul.pt (A.M. Fortes).
} 
has been proposed as the main signal triggering the onset of ripeningassociated processes since it peaks at veraison, along with initiation of berry softening and skin coloration [6]. Increases in the levels of ABA also influence the accumulation of sugars, and their enhanced uptake and storage can be stimulated by exogenous application of ABA before veraison [7]. Treating grape berries with $\mathrm{ABA}$ at pre-veraison or veraison can also contribute to improve anthocyanin levels and the biosynthesis of phenylpropanoids $[8,9]$. The endogenous ABA content is determined by the dynamic balance among biosynthesis, conjugation and catabolism [10].

Auxins play an important role in fruit growth, but act as inhibitors of ripening in both climacteric and non-climacteric fruits [11]. Low auxin levels seem to be required at the onset of grape ripening, which is associated with an increase in the conjugated forms of indole-3-acetic acid [12]. Auxin delays increase in berry size, sugar accumulation, and anthocyanin content; in fact, auxin negatively regulates ABA-induced ripening processes [13-15]. Nevertheless, a core set of several genes involved in auxin signaling has been found to be differentially expressed during grape ripening of three cultivars [16]. In tomato, altered AUXIN RESPONSE FACTOR 2 expression leads to modified contents in $\mathrm{ABA}$, cytokinins and salicylic acid highlighting that auxin signaling intersects hormonal signals in the regulation of fruit ripening [17].

As noticed for auxins, jasmonic acid (JA) levels together with expression of genes involved in jasmonate biosynthesis are higher during early development and decrease during ripening. This appears to enable the onset of ripening to occur [18]. Nevertheless, jasmonic acid has been suggested to be involved in ripening by influencing the coloring, softening and aroma of the fruit [19]. A volatile form of JA, methyl jasmonate, promotes red coloring, increase in anthocyanin content and volatiles' synthesis when exogenously applied on fruit [20,21]. Additionally, JA is known to regulate plant immune responses in particular against necrotrophic pathogens, e.g. Botrytis cinerea [22,23]. B. cinerea is a fungus to which several varieties of grapevine are highly susceptible in particular the Portuguese Trincadeira [4].

Salicylic acid has been described to be involved in the activation of plant defenses against fungal pathogens, biotrophs and hemibiotrophs, but it may induce susceptibility to necrotrophs by antagonizing the JA signaling pathway and by inhibition of auxin signaling [22,24]. Salicylic acid signaling was shown to enhance susceptibility in mature/ ripe tomato fruit by promoting cell death and likely by suppressing JA mediated defense response during necrotrophic colonization stage of Colletotrichum [25]. However, in unripe tomato fruit the transgenic NahG tomato line, which does not accumulate SA, showed susceptibility to Botrytis [26]. These findings highlight that SA may contribute to susceptibility or resistance depending on the ripening stage.

Besides SA and jasmonates, which are conserved positive regulators of plant defense, auxins are hormones with emerging roles in plant defense response [27,28]. Previous studies suggested that auxins may also be involved in the grape response to Botrytis infection [4]. Interestingly, an interaction between auxin and jasmonic acid was previously shown to occur in resistance to necrotrophic pathogens [29].

On the other hand, ABA has been described as a hormone that can either induce or repress plant defense depending on the specific plant-pathogen interaction [24,30]. It is generally assumed that ABA suppresses plant resistance mechanisms by interfering with SA- and JA/ ET-dependent immune responses [31], though few examples associated ABA with disease resistance [30]. Additionally, during infection, certain plant pathogens can directly produce ABA or induce its synthesis in the host in order to accelerate fruit ripening and therefore fruit susceptibility [32]. Overall synthesis and perception of different stress hormones, along with their relative contents and interactions, seem to be crucial for plant resistance against pathogens.

Previously, transcriptome analysis of Vitis vinifera cv. Trincadeira berries upon infection with $B$. cinerea suggested the putative involvement in grape defense of jasmonic acid, ethylene, and auxins [4]. This innovative study focused on the fruit organ since defense mechanisms against fungal pathogens have been documented mostly for vegetative tissues [24]. In the present study, were compared a highly susceptible variety (Trincadeira) that presented heavy symptoms of infection at an early stage of ripening, and a highly resistant/ tolerant variety (Syrah) of grape that was only infected at harvest stage $[4,33]$. New developmental stages were taken into account allowing deepening the understanding of hormone regulation during grape ripening and grape defense against Botrytis cinerea. The expression of genes related to hormonal metabolism and signaling, as well as the analysis of the hormonal profile was carried out in order to unravel cultivar specific mechanisms involved in the onset of ripening and in effective defense.

\section{Materials and methods}

\subsection{Infection of berries and sample collection}

Field experiments were conducted in an experimental vineyard with 15-year-old grapevines (rootstock '140Ru') at the Instituto Superior de Agronomia, University of Lisbon, Portugal. Infections of Vitis vinifera cv Trincadeira and Syrah berries with Botrytis cinerea were made in June of 2016. The $B$. cinerea isolate used was obtained from diseased grapevine plants and maintained in potato dextrose agar (Difco, Detroit, MI, USA), at $5{ }^{\circ} \mathrm{C}$. Conidia production was obtained by exposing inoculated Petri dishes with potato dextrose agar to continuous fluorescent light, at $24^{\circ} \mathrm{C}$. Conidia were harvested from 14- to 20-day-old cultures and collected by rubbing with phosphate buffer $\left(0.03 \mathrm{M} \mathrm{KH}_{2} \mathrm{PO}_{4}\right)$, filtered through cheesecloth to remove mycelia, and the concentration adjusted to $10^{5}$ conidia $\mathrm{ml}^{-1}$. The infections were made by spraying berry clusters with a conidial suspension at the developmental stage of peppercorn size (stage EL29, $14^{\text {th }}$ June), following the procedure by AgudeloRomero et al. [4]. Collection of Trincadeira and Syrah samples after visual inspection of symptoms was performed at three different stages of development/ ripening: green (stage EL32; $14^{\text {th }}$ July), veraison (stage EL35; $27^{\text {th }}$ July) and harvest (stage EL38; $20^{\text {th }}$ September) according to the modified E-L system [34]. Five to six replicates were obtained for each stage of development and for each treatment (control sprayed with phosphate buffer), and all berry clusters were briefly transported in ice to the laboratory, frozen in liquid nitrogen and kept at $-80^{\circ} \mathrm{C}$ until further use. Previous phenotypic, molecular and biochemical analyses showed that treatment of grapes with buffers had no visible impact on grape ripening [35]. Prior to extraction for transcriptional and metabolic analyses, the seeds were removed. Four to six biological replicates were used for quantification of hormones and some of these samples were pooled in order to yield three independent biological replicates for study of gene expression.

\subsection{DNA extraction and assessment of Botrytis cinerea infection with $q P C R$}

DNA extraction was performed according to Lodhi et al. [36] with modifications: a $2 \mathrm{M}$ KAc treatment ( $1 \mathrm{~h}$ on ice) to precipitate polysaccharides was added to the protocol and performed before RNase A treatment. Fungal biomass accumulation and infection level was determined by qPCR amplification of the $B$. cinerea polygalacturonase 1 (PG1). DNA accumulation levels were linearized with the formula $2^{-}$ $(\mathrm{BCPG1} \mathrm{Ct}-\mathrm{VvACT} \mathrm{Ct})$ using the grape actin gene as reference.

\subsection{RNA extraction}

RNA extraction was carried out according to Fortes et al. [18] with slight modifications: the KAc treatment for polysaccharides removal was done before overnight RNA precipitation with $\mathrm{LiCl}$ in order to avoid an additional precipitation with sodium acetate and ethanol. A DNase treatment was performed according to the supplier's instructions (Invitrogen, San Diego, CA, USA). RNA was further purified using the Spectrum $^{\text {TM }}$ Plant Total RNA Kit (Sigma-Aldrich). 


\subsection{Real-time PCR}

First-strand cDNA was synthesized from $2 \mu$ g of total RNA as described previously [18]. Real-time PCRs were performed using the StepOneTM Real-Time PCR System (Applied Biosystems, Foster City, CA, USA). Cycling conditions were $95^{\circ} \mathrm{C}$ for $10 \mathrm{~min}$, followed by 42 cycles of $95^{\circ} \mathrm{C}$ for $15 \mathrm{~s}$ and $56^{\circ} \mathrm{C}-60^{\circ} \mathrm{C}$ for $40 \mathrm{~s}$. Relative expression data were derived from three biological replicates and duplicate technical replicates (performed in separate plates). The standard curve was built using a serial dilution of mixtures of all cDNAs analyzed. Primer efficiencies (in between 85 and 105\%) were calculated using 4-fold cDNA dilutions $(1: 1,1: 4,1: 16,1: 64$, and 1:256) in triplicate as well as checking for amplification in a negative control without DNA. In order to obtain relative expression of the genes under study, data were normalized using the expression curves of the actin gene (VIT_04s0044g00580) and elongation factor $1 \alpha$ gene (VIT_06s0004g03220). These genes are the most stable according to NormFinder software [4]. All primers used are shown in Supplementary Table S1. Selection of the genes involved in hormonal metabolism for qPCR analysis was based on previous microarray data [4], analyses of hormonal pathways (Supplementary Fig. S1) and bibliography (Supplementary Table S2).

\subsection{Hormonome analysis}

Stock solutions of each original phytohormone standard were prepared at $1 \mathrm{mg} \mathrm{ml}^{-1}$ in $\mathrm{MeOH}$. For deuterated compounds, stock solutions were prepared in acetonitrile at $100 \mu \mathrm{g} \mathrm{ml}^{-1}$. Working solutions of original phytohormones standards were prepared by diluting stock solutions in $\mathrm{MeOH}$ :water (7:3), at different concentration for each phytohormone depending on the range of the calibration curve: $\mathrm{ABA}$ and IAA at $100 \mu \mathrm{g} \mathrm{ml}^{-1}$; JA and SA at $200 \mu \mathrm{g} \mathrm{ml}^{-1}$; 12-oxo-phytodienoic acid (OPDA) at $50 \mu \mathrm{g} \mathrm{ml}^{-1}$; and conjugate jasmonoyl isoleucine (JA-Ile) at $40 \mu \mathrm{g} \mathrm{ml}^{-1}$. The internal standard stock solutions (d5-JA, d6-ABA, d4$\mathrm{SA}$, and d5-IAA) were combined and diluted in $\mathrm{MeOH}$ :water (7:3) ratio, resulting in the extraction solution. The final concentrations were $10 \mathrm{ng}$ $\mathrm{ml}^{-1}$ for both d4-SA and d5-IAA, and $20 \mathrm{ng} \mathrm{ml}^{-1}$ for both d5-JA and d6ABA.

The samples (5-6 biological replicates) were freeze dried at $-40{ }^{\circ} \mathrm{C}$ for three days. One $\mathrm{ml}$ of extraction solution containing the internal standards (d5-JA, d6-ABA, d5-IAA, and d4-SA), prepared as described previously, was directly added. The samples were briefly mixed with a vortex, and spiked with phytohormones standards as described in Almeida Trapp et al. [37]. The spiked samples were shaken for $30 \mathrm{~min}$ and centrifuged at $16,000 \times g$ and $4{ }^{\circ} \mathrm{C}$ for $5 \mathrm{~min}$. The supernatant was transferred into a new micro-centrifuge tube and dried in speed vac. After drying, $100 \mu \mathrm{l}$ of $\mathrm{MeOH}$ were added to each sample, which were then mixed with a vortex and centrifuged at $16,000 \times g$ and $4{ }^{\circ} \mathrm{C}$ for $10 \mathrm{~min}$. The supernatant was analyzed by HPLC-MS/MS (high performance liquid chromatography-mass spectrometry) as described [37]. Quantification of phytohormones was based in the ratio: peak area of certain compound (hormone)/ peak area of internal standard (comp/ IS), corrected by the dry weight.

\subsection{Anthocyanin quantification}

Anthocyanin concentration was measured as described previously [18]. Grapes were frozen in liquid nitrogen, seeds removed, freezedried for $72-96 \mathrm{~h}$ at $-40^{\circ} \mathrm{C}$ and then $100 \mathrm{mg}$ of the powder extracted in $1.5 \mathrm{ml}$ TFA (Trifluoroacetic acid)/methanol/ $\mathrm{H}_{2} \mathrm{O}(0.05 / 80 / 20, \mathrm{v} / \mathrm{v} / \mathrm{v})$. Samples were vortexed for $1 \mathrm{~min}$ and then anthocyanins were extracted for $1 \mathrm{~h}$ on ice in Eppendorf tubes. The mixture was then centrifuged for $30 \mathrm{~min}$ at $13,000 \mathrm{rpm}$ at $4{ }^{\circ} \mathrm{C} \mathrm{A} 50 \mu \mathrm{l}$ or $100 \mu \mathrm{l}$ of this sample was diluted to $1 \mathrm{ml}$ in extraction solution for veraison and harvest samples. The solution was mixed and allowed to sit for $5 \mathrm{~min}$ before reading the absorbance at $\mathrm{A}_{520}$. Total relative anthocyanin concentration was expressed as the absorbance value at $520 \mathrm{~nm} \mathrm{~g}^{-1}$ of freeze-dried weight.

\subsection{Statistical analysis}

In order to identify the significance of genotype or treatment on gene expression or phytohormones content, all data were analyzed by two-way ANOVA. In the cases where the residuals were not normally distributed and/or the variance was not equal among the groups, the data were prior transformed, to be further tested with ANOVA. For the analyses of phytohormones, some outliers were identified by two-tailed Dixon's Q-Test (with $Q=95 \%$ ) and excluded before the two-way ANOVA. All data were analyzed with Sigma Plot (version 12.0).

\section{Results}

3.1. Phenotypic characterization of infected and mock-treated grape berries and assessment of Botrytis cinerea infection

Berries were inoculated with $B$. cinerea conidial suspension at the peppercorn-sized fruits stage corresponding to developmental stage EL29 [34]. The ripening stages considered in this study were EL32 characterized by hard green berries, EL35 corresponding to veraison when anthocyanin accumulation initiates, and EL38 corresponding to fully ripe berries (harvest stage).

Fig. 1 shows infected Trincadeira and Syrah clusters corresponding to EL32, EL35 and EL38. Trincadeira clusters showed already at EL32 a high infection level with $B$. cinerea. Evaluation of sample infection was performed by visual inspection and additionally by qPCR using primers specific to the fungal genomic DNA (Fig. 2). Syrah present very mild symptoms at EL32 which was corroborated by the qPCR analysis (Fig. 2). Though symptoms increase during ripening Syrah still presented at EL38 a lower level of infection than Trincadeira which is not surprising since Syrah is known to be tolerant/ resistant to the disease under normal in-field conditions [33].

The assessment of ripening stages took into account the fresh berry weight and the content in anthocyanins present in healthy berries (Fig. 3). Content in anthocyanins has been described as a reliable indicator of the ripening stage [38]. Additionally, recent metabolomics data did not show significant differences in the main ripening parameters between control berries of the two cultivars (data not shown). As results of $B$. cinerea infection on Trincadeira, a decrease in berry weight in infected compared with non-infected samples and an increase in anthocyanin content at EL35 were detected, indicating that infected berries were riper than non-infected berries as previously noticed and supported by molecular and metabolic data [4]. The acceleration of ripening as assessed by berry weight and anthocyanin content was not observed for less infected Syrah berries.

On the other hand, the content in anthocyanins at EL38 decreased significantly in the severely infected Trincadeira but not in Syrah. This decrease in anthocyanins was previously observed in berries severely infected with powdery mildew [39] and in grape skins of Botrytis-affected berries [40].

\subsection{Hormonal metabolism of Trincadeira and Syrah cultivars during grape ripening}

For jasmonate analyses we focused on the bioactive form, jasmonoyl-isoleucine conjugate (JA-Ile) [41], and its biosynthetic precursor 12-oxo-phytodienoic acid (OPDA). At EL32, both cultivars showed similar amounts of OPDA and started decreasing from the onset of grape ripening until EL38 (Fig. 4). In case of JA-Ile, a decrease from EL32 to EL38 was also found in both cultivars; however, at EL32 the JA-Ile concentration in Syrah grapes was about three times higher than in Trincadeira and at EL35 it was still higher. The expression of a gene coding for allene oxide synthase (AOS) involved in OPDA synthesis 

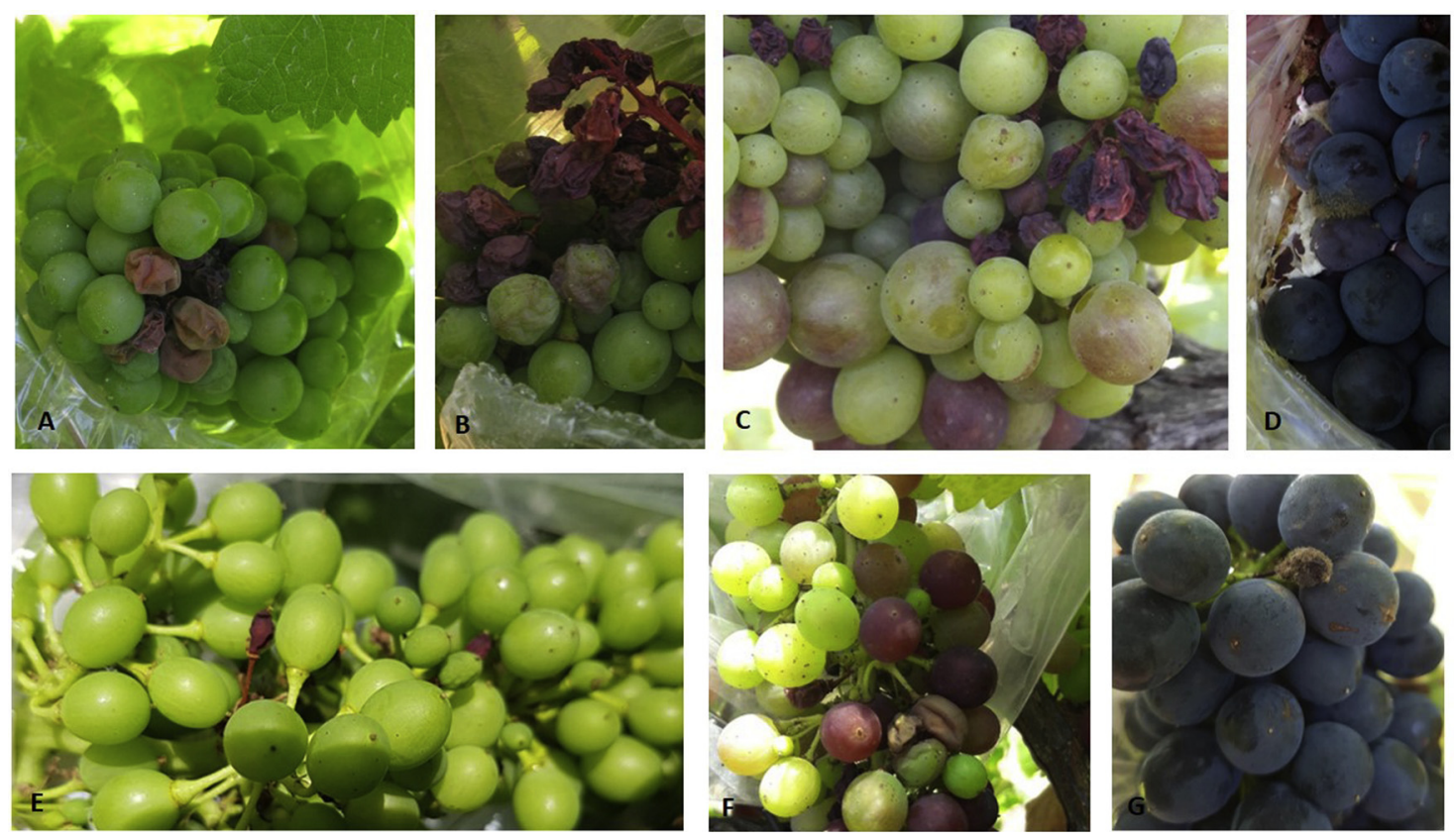

Fig. 1. Clusters of Trincadeira and Syrah grapes infected with B. cinerea. A, B Clusters of Trincadeira at EL32. C, Cluster of Trincadeira at EL35. D, Cluster of Trincadeira grapes at EL38. Sporulation of the fungus is observed in some berries of the cluster. E, Cluster of Syrah at EL32 with no significant symptoms. F, Cluster of Syrah at EL35. G, Cluster of Syrah grapes at EL38.

(Supplementary Fig. S1) showed a pronounced increase during ripening of Trincadeira grapes. Another biosynthetic gene encoding 12-oxophytodienoate reductase 1 (OPR1) and further involved in JA-Ile biosynthesis tended to be slightly higher at the green stage (EL32) in both cultivars in accordance with the concentration of JA-Ile. However, at EL35 Trincadeira presented higher expression of this gene but lower JA-Ile levels. A gene coding for JAZ8, a repressor of jasmonate signaling [42] was up-regulated at EL38 in both Trincadeira and Syrah grapes. MYC2 expression involved in jasmonate- dependent transcriptional activation [28], presented an expression pattern during grape ripening similar to JAZ8 but with a lower fold-change level.

Similar to jasmonates the content in IAA showed a tendency to decrease in Syrah and Trincadeira grapes during ripening (Fig. 5). The highest expression levels of the gene coding for Indole-3-acetic acidamido synthetase, GH3.2, involved in auxin inactivation by conjugation [43] were at stage EL32 in accordance with IAA content. The expression of this gene lowers along grape ripening, and more abruptly in Syrah grapes. Expression of IAA-amino acid hydrolase 6 was higher at EL32 compared with EL35 but tended to increase at EL38. In both cultivars, the amount of IAA reached its lowest content at the harvest stage, though higher in Trincadeira.

Small Auxin Up RNAs (SAURs) are the largest family of early auxin response genes (Supplementary Fig. S1) and some members can act as negative regulators of auxin biosynthesis [44]. The auxin-responsive SAUR29 gene presented lower levels of expression at stage EL32 in accordance with the peak of auxin content observed in both cultivars at this stage. As the expression of the auxin-responsive SAUR29 increased, auxin concentration decreases, until the gene reached its peak of expression at stage EL38. The same was verified for Aux1 involved in auxin transport [45]. Interestingly, the expression of $A u x 1$ was higher in Trincadeira at EL38 whereas the expression of auxin-responsive SAUR29 was higher in Syrah at EL35.

Regarding SA concentrations they steadily decreased across the various stages of ripening, both in Syrah and in Trincadeira grapes (Fig. 6). The expression of genes coding for enhanced disease susceptibility (EDS1) and phytoalexin deficient 4 (PAD4) involved in SA signaling [46] also followed this trend in both cultivars. Out of the two cultivars, Syrah displayed at EL32 higher basal levels of SA than Trincadeira and higher expression of PAD4.

While jasmonates and auxins decreased during ripening, $A B A$

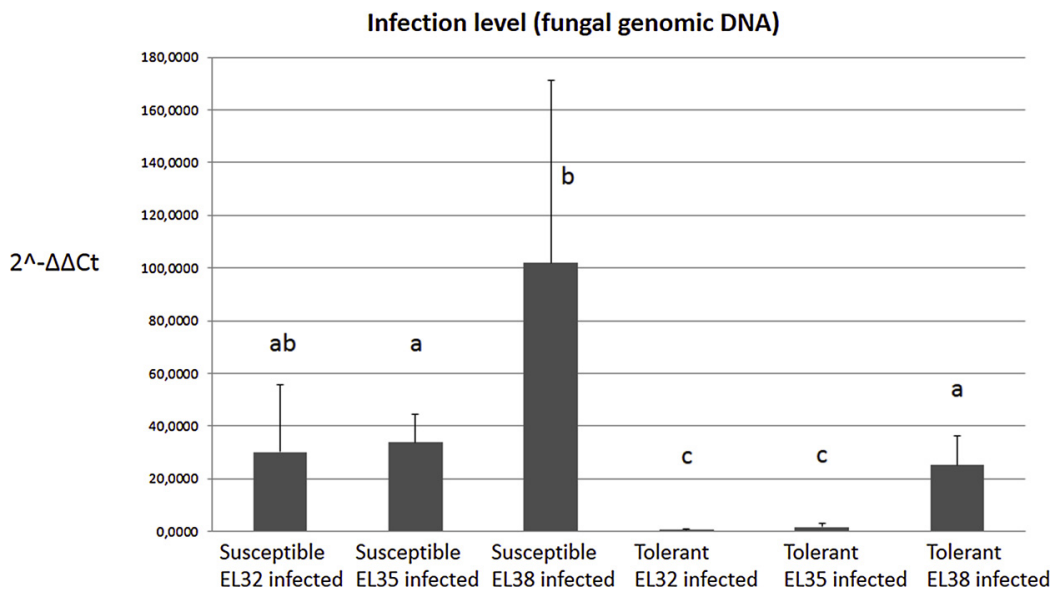

Fig. 2. Evaluation of infection level by $q \mathrm{PCR}$ using primers specific to the fungal genomic DNA (BcPG1). Syrah (tolerant) presented very mild infection at EL32 whereas Trincadeira (susceptible) was severely infected. Bars represent the standard deviation error. Data were analyzed with Welch's t-test. Different infection level is given by different lettering ( $\mathrm{p}<0.05)$. 
A

\section{Berry weight}

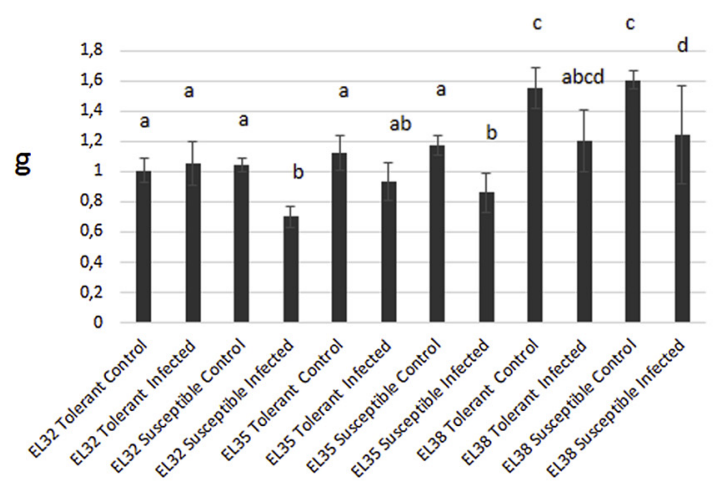

B

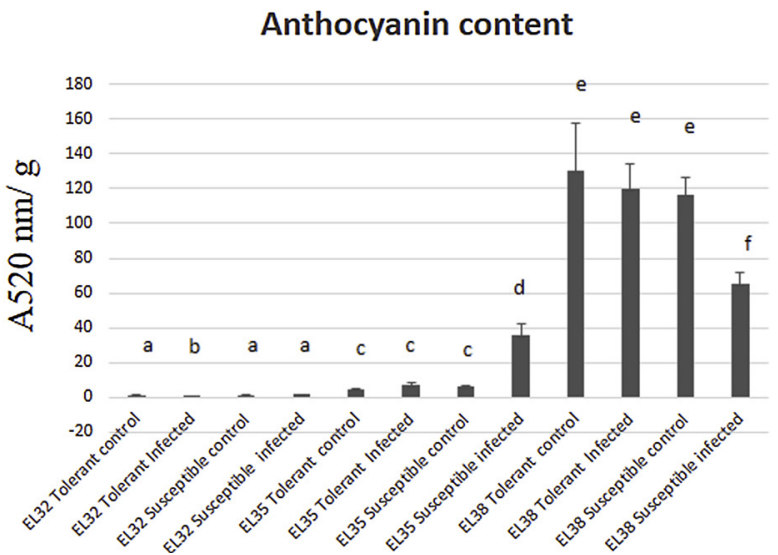

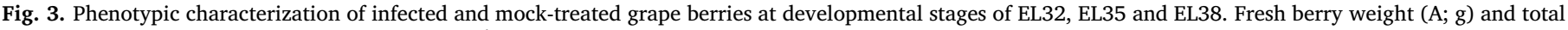

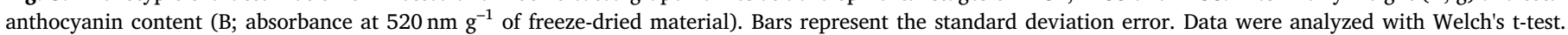
Different infection level is given by different lettering $(\mathrm{p}<0.05)$.

concentration increased drastically at veraison in both Trincadeira and Syrah grapes and decreased again at harvest (Fig. 7). The levels of expression of gene coding for 9-cis-epoxycarotenoid dioxygenase (NCED) involved in ABA biosynthesis (Supplementary Fig. S1) was higher at veraison in both cultivars and about two times in Syrah at EL35. These data are in general in accordance with the variations in ABA content showed by hormone quantification. Interestingly, the gene coding for ABA receptor PYL4 RCAR10 involved in ABA-mediated signaling pathway [47] was more expressed during the green stage, especially in Syrah grapes. In fact, at EL32 when compared with Trincadeira, Syrah grapes presented higher expression of NCED, and ABA receptor PYL4 RCAR10, though levels of ABA were similar for both cultivars. The expression of this ABA receptor was more noticeable in Trincadeira grapes at harvest, possibly related to a higher content in ABA in this cultivar at this stage.

3.3. Hormonal metabolism of Trincadeira and Syrah grapes upon infection with Botrytis cinerea

Concerning jasmonates, at EL32, the amount of OPDA in Syrah

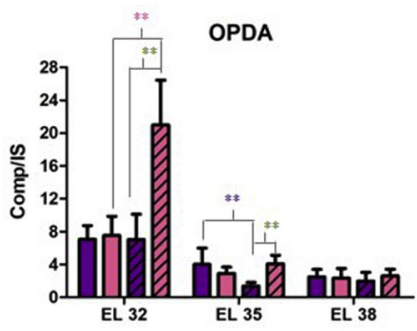

B

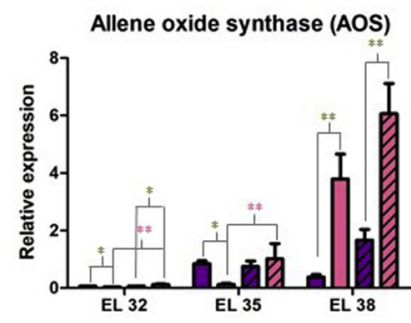

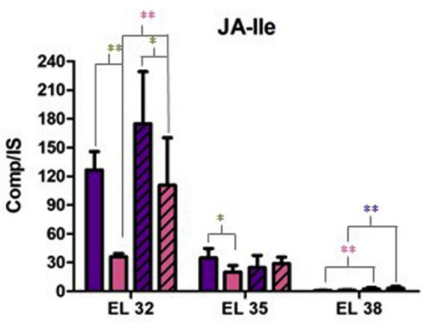

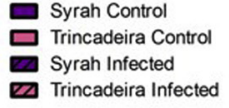

12-oxophytodienoate reductase 1 (OPR1)

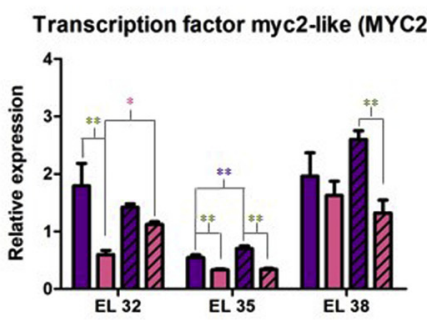

Jasmonate ZIM domain-containing protein 8 (JAZ8)

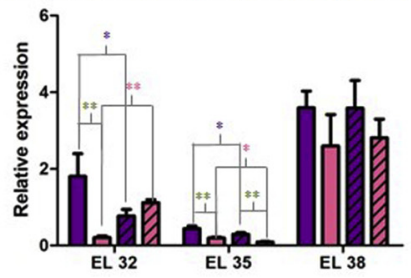

Fig. 4. Metabolism of jasmonates in Trincadeira and Syrah grapes at three development stages: green (EL32), veraison (EL35) and harvest (EL38). A, Hormonal quantification of jasmonates (OPDA and JA-Ile); B, Expression of genes involved in jasmonates metabolism: AOS, OPR1, MYC2 and JAZ8. Data were analyzed by twoway ANOVA: * $\mathrm{P}<0.05 ;{ }^{*} \mathrm{P}<0.01$. Different colors present either intra or inter-variety comparisons (For interpretation of the references to colour in this figure legend, the reader is referred to the web version of this article). 
A
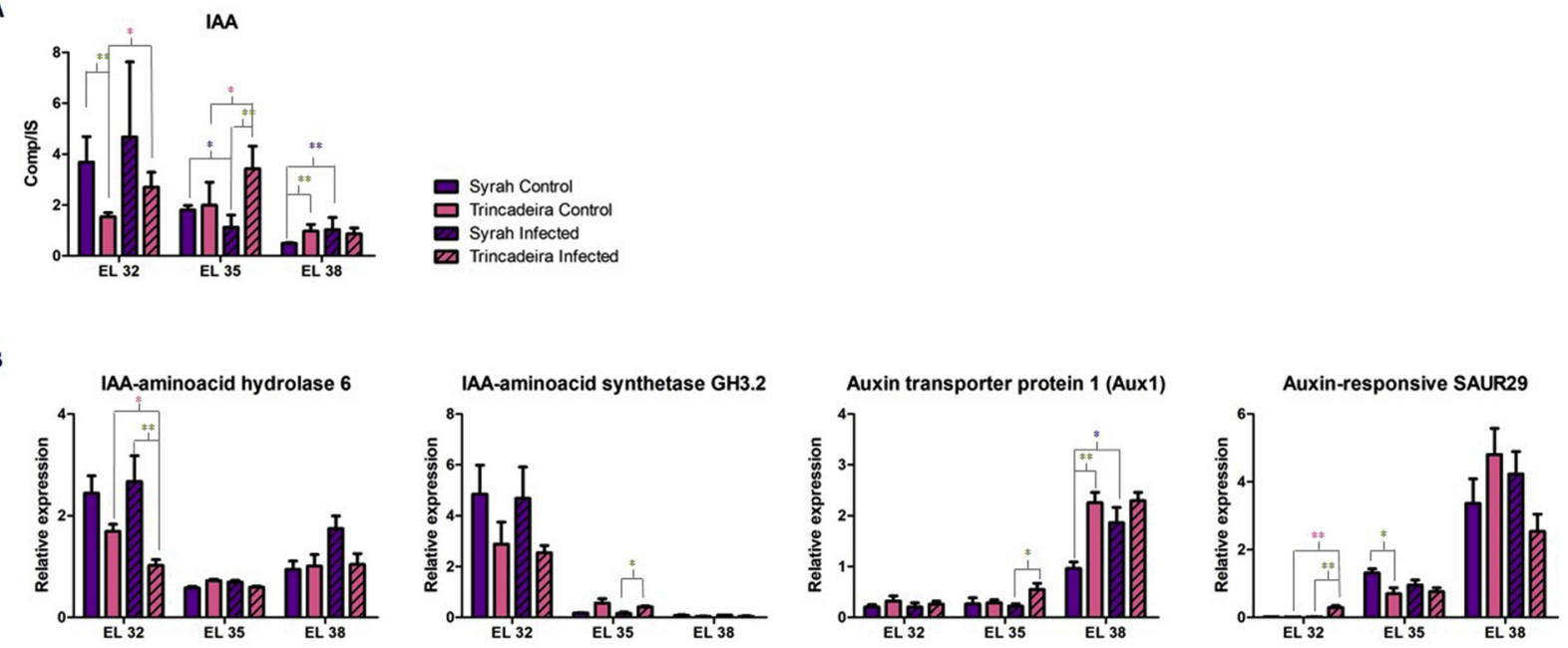

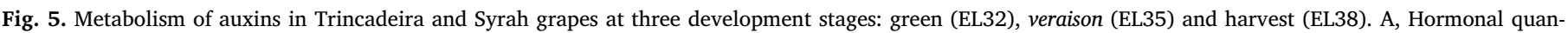

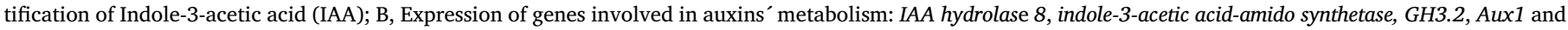

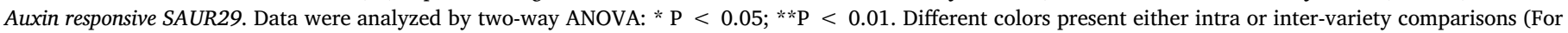
interpretation of the references to colour in this figure legend, the reader is referred to the web version of this article).

grapes was maintained after infection, while in the susceptible Trincadeira variety, which already showed heavy symptoms, OPDA level increased (Fig. 4). The same held true for JA-Ile. However, Syrah grapes displayed higher basal levels of JA-Ile comparing to Trincadeira along with higher expression of MYC2 and JAZ8. Regarding the expression of genes involved in the synthesis of jasmonic acid, it was noted that at green stage expression of AOS was very low in infected samples of both cultivars though differences could be noted between them. However, at harvest expression of AOS increased in infected berries of Syrah and Trincadeira, being highly expressed in the later one. The expression of this gene is in general in agreement with the content in JA-Ile at harvest stage. On the other hand, OPR1 expression peaked at the green stage, which is in accordance with the concentration of JA-Ile. Particularly, it illustrates the increase in JA-Ile concentration in Trincadeira grapes upon infection accompanied by higher expression of JAZ8 whereas the opposite was noticed in Syrah regarding the expression of this repressor of jasmonic acid signaling.
OPR1 expression decreased at veraison accompanied by a decrease in the content in JA-Ile. Interestingly, at EL38 infected Syrah grapes seem to present higher expression of $O P R 1$ than Trincadeira but this was not reflected in increased JA-Ile levels. It should be noted that only at this stage Syrah grapes presented heavy symptoms of infection.

Regarding auxins, the content in IAA increased in infected Trincadeira grapes at EL32 and EL35 while the expression of IAA-amino acid hydrolase 6 decreased in this cultivar at EL32 (Fig. 5). On the other hand, at EL35 levels of IAA seem to be mainly regulated in the two infected cultivars by different expression of Indole-3-acetic acid-amido synthetase. Although not statistically significant $(\mathrm{p}<0094)$, the higher basal levels of expression of IAA-amino acid hydrolase 6 in Syrah grapes at EL32 are accompanied by higher IAA content observed at this stage. Additionally, at EL32 only infected Trincadeira berries showed increased expression of the gene coding for auxin responsive SAUR29 whereas AUX1 increased in Syrah infected grapes at EL38. This suggests different regulation of auxin signaling and transport during ripening of

A

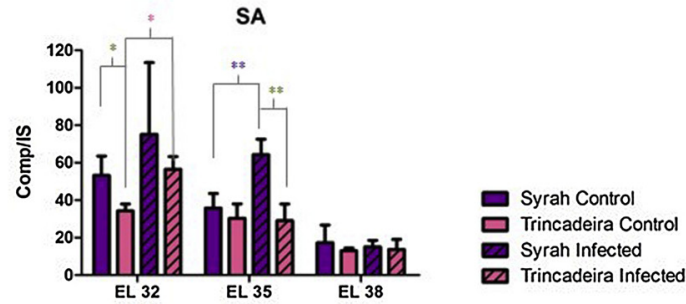

B

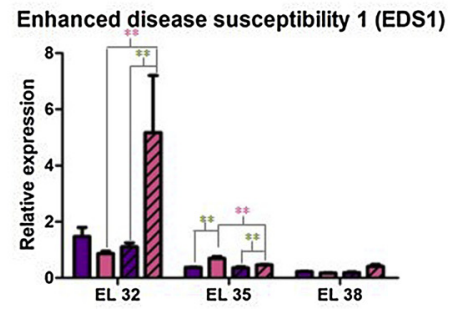

Phytoalexine deficient 4 (PAD4)

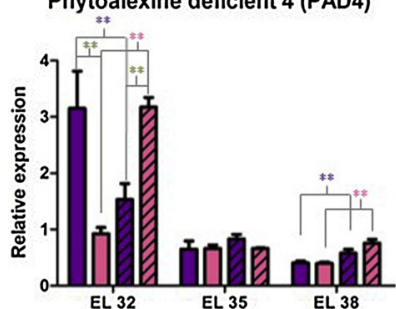

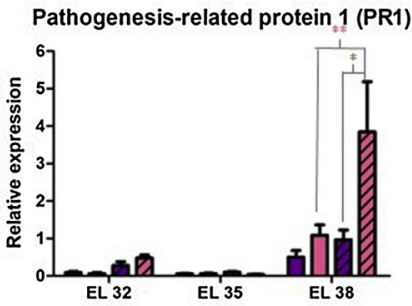

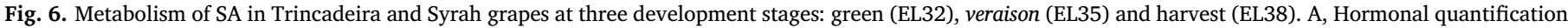

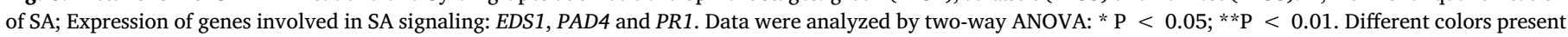

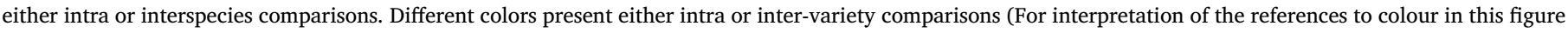
legend, the reader is referred to the web version of this article). 
A

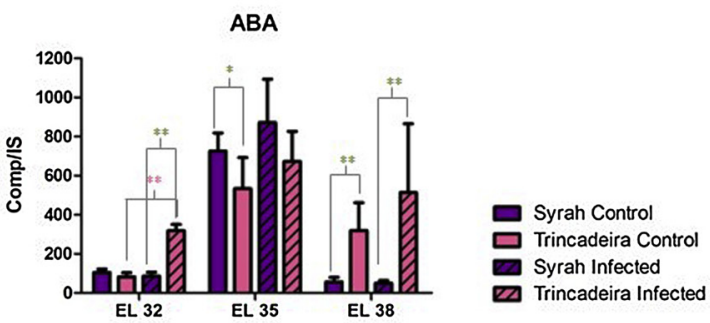

B
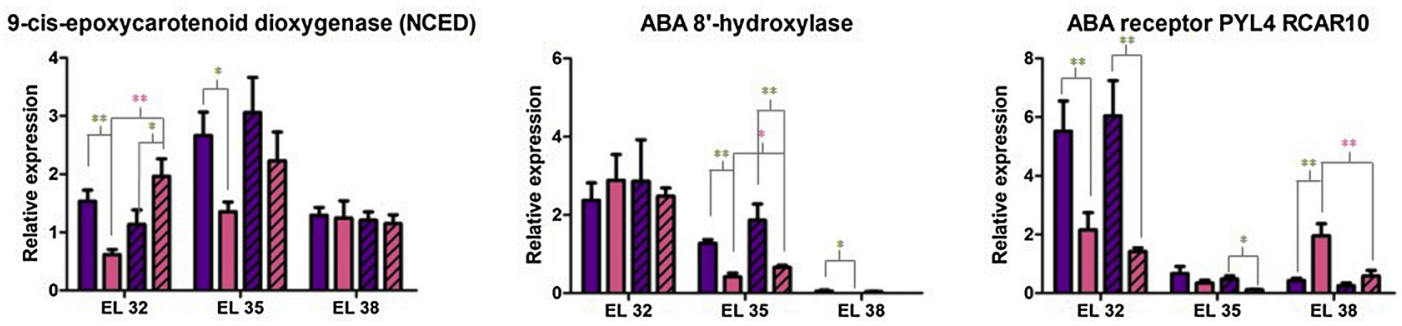

Fig. 7. Metabolism of ABA in Trincadeira and Syrah grapes at three development stages: green (EL32), veraison (EL35) and harvest (EL38). A, Hormonal quantification of ABA; Expression of genes involved in ABA metabolism: 9-cis-epoxycarotenoid dioxygenase (NCED), ABA receptor PYL4 RCAR10, ABA 8'-hydroxylase. Data were analyzed by two-way ANOVA: * $\mathrm{P}<0.05 ;{ }^{* * \mathrm{P}}<0.01$. Different colors present either intra or interspecies comparisons. Different colors present either intra or inter-variety comparisons (For interpretation of the references to colour in this figure legend, the reader is referred to the web version of this article).

infected berries from different cultivars.

On the other hand, SA levels were shown to accumulate more upon infection at EL32 in Trincadeira, and at EL35 in Syrah grapes (Fig. 6). At the harvest stage, SA content was relatively the same in both grape cultivars after being infected. Interestingly, the green stage was marked by high levels of expression of the genes coding for EDS1 and PAD4 in infected Trincadeira grapes. Accordingly, Trincadeira grapes showed a larger increase of SA upon infection at this stage. Noteworthy is the higher basal level of expression of PAD4 in Syrah grapes at EL32 together with higher basal levels of SA. EDS1 and PR1 seem to follow the same trend but the differences were not statistically significant. EDS1 and PAD4 expression levels were lower at veraison and at harvest in both cultivars but PR1 increased at EL38 especially in infected Trincadeira berries.

In what concerns ABA, it displayed a larger increase in concentration in the Trincadeira cultivar upon infection, in particular at EL32 (Fig. 7). On the other hand, at EL35 infected Syrah berries presented higher expression of $A B A$ 8'-hydroxylase and $A B A$ receptor PYL4 RCAR10 when compared with infected Trincadeira berries.

The expression pattern of NCED at EL32 and EL35 was very similar to the observed content in $\mathrm{ABA}$ for the variety of samples but not at EL38. The expression of the gene coding for ABA receptor PYL4 RCAR10 was higher at green stage, especially in Syrah grapes. At EL38, the expression of this gene decreased in Trincadeira berries upon infection. At this stage, infected Trincadeira berries exhibiting heavier symptoms of infection presented higher content in ABA than infected Syrah berries.

\section{Discussion}

Hormones play an important role in plant development and stress responses. Disclosing the roles hormones have in grape ripening and grape defense against major fungal pathogens will enable improvement of fruit traits and productivity. In this context, hormonomics may provide invaluable cues concerning hormonal crosstalk occurring in diverse plant processes. However, concentrations of plant hormones are often very low, thus requiring a highly sensitive MS detection system [48]. Hormonomics has been rarely reported in fruit research, pathogen response and also in general plant science. Oikawa et al. [49] have reported comprehensive phytohormone analysis on pear. The majority of plant hormones (e.g. IAA, JA, JA-Ile, SA) presented high content in the youngest fruit and then decreased dramatically. ABA was among the few hormones that increased in the ripening stage. Similar results were obtained in the present study focusing in grape ripening and they were confirmed for two cultivars bringing robustness to the study.

4.1. Combined study of two cultivars highlighted differences in the metabolism of $A B A$, auxins and jasmonates during grape ripening that may influence berry quality

The important role played by $\mathrm{ABA}$ in the onset of grape ripening has been widely referred [1,50,51]. Increases in $A B A$ in the absence of significant increases in expression of the $V$. vinifera 9-cis-epoxycarotenoid dioxygenases were previously proposed during early softening [52]. These increases were accompanied by decreases in a product of ABA catabolism, suggesting that initial increases in ABA may be due to decreases in catabolism and/or exogenous import. The simultaneous study of grapes from two cultivars collected in the same region validated the great increase in ABA at initial veraison and a putative decrease in ABA catabolism. However, differences between the two cultivars were more pronounced in relation to the expression of NCED at EL32 and EL35. Syrah also exhibited a lesser abrupt decrease in ABA catabolism throughout ripening as assessed by the expression of $A B A 8^{\prime}$ hydroxylase, which was lower in Trincadeira at EL35 and EL38. Furthermore, the metabolism of ABA is also different between Syrah and Trincadeira at harvest stage with Trincadeira accumulating significantly more ABA (likely due to a higher decrease in ABA catabolism) and transcripts of a gene coding for ABA receptor PYL4 RCAR10 but registering no significant difference in NCED expression.

Therefore, ABA biosynthesis, catabolism and signaling are dependent on the cultivar and also on the ripening stage. Recently, the effects of $A B A$ on different organs of grapevine were tested and indicated that ABA signaling varies with the organ [53]. It may be that it also varies with the tissue; therefore differences in ABA metabolism between skin and pulp may partially account for the differences noticed here between the whole berries of the two cultivars. Additionally, ABA may have an impact in fruit quality [54] and Trincadeira and Syrah are known to produce grapes and wines with different features. In fact, recent studies 
have shown that exogenous treatment of pre-veraison grape berries with ABA activated the expression of genes involved in cell wall modification, lipid, carbohydrate and flavonoid metabolisms [51].

Contents in auxins and jasmonates are known to decrease during grape ripening while some signaling processes of these growth regulators are activated [1,18]. However, these aspects have not been previously compared between cultivars collected in the same region. Interestingly, the contents in IAA and the expression of a gene coding for auxin-responsive SAUR29 varied in between the cultivars across the developmental stages. Previously, a role of SAUR proteins in promoting cell expansion was described [55] and this process occurs during berry ripening. Additionally, differences in the expression of gene coding AUX 1 were noticed between the two cultivars at harvest but not in genes coding for enzymes involved in auxin glycosylation/ hydrolysis though higher content in IAA was observed in Trincadeira at this stage. Since auxin is known to delay increases in berry size, sugar and anthocyanin accumulation $[12,13,15]$ the fine regulation of the pool of free IAA and its conjugates together with auxin transport (e.g. AUX1) and signaling may have an impact on final berry quality. Moreover, auxin negatively regulates ABA-induced ripening processes [15] and interactions between ethylene and auxin were reported to be crucial to regulation of berry ripening [56].

Another level of complexity can be added with the participation of jasmonates in the regulation of berry development and ripening as previously suggested [19]. While differences in JA-Ile content were not noticed between cultivars at harvest stage, they were noticed at EL32 and EL35 with Syrah exhibiting more JA-Ile and higher expression of MYC2 and jasmonate ZIM domain-containing protein 8 (JAZ8). Recently, a putative mechanistic link was reported connecting ABA and JA signaling pathways through a direct interaction of the ABA receptor PYL6 (RCAR9) with the transcription factor MYC2 [47]. The expression of the two genes coding for these receptor and transcription factor followed a similar pattern at EL32 and EL35 for both cultivars though expression levels were generally higher in Syrah. The same was not verified at EL38 when comparing both cultivars indicating that the interplay among hormones is strictly regulated during ripening and depends on the genetic background. In fact, many examples of crosstalk among hormones have been described in grape [1]; the present results suggest that this crosstalk is likely to occur with specificities associated with each cultivar.

Salicylic acid antagonizes ABA signaling [57] and may delay ripening as suggested by the decrease in its content in both cultivars. Additionally, SA treatment has been found to delay the ripening of both banana and grape fruits [58,59]. Interestingly, PAD4 and EDS1 were shown to regulate cell wall properties in poplar [60] and may eventually play a role in regulation of berry softening. At veraison and harvest stage no clear differences were noticed between cultivars in what concerns the content in SA as well as in the expression of genes coding for EDS, PAD4 and PR1. Though it can be suggested that the role of SA in influencing berry quality characteristics specific of each cultivar may be less determinant than other hormones, its function in grape ripening may still be uncovered.

4.2. Tolerance against Botrytis cinerea may be determined by higher basal content in salicylic acid, jasmonates and auxins and additional induced synthesis of salicylic acid

The analysis of the hormonome showed that Syrah presented at EL32 higher content in SA, JA-Ile and IAA, suggesting that these hormones are involved in basal resistance against $B$. cinerea. Salicylic acid is known to be crucial in basal defenses, effector-triggered immunity, and local and systemic acquired resistance [61-63]. Additionally, SA has been described as involved in the activation of plant defenses against biotrophs and hemibiotrophs, and it may also enhance susceptibility to necrotrophs by antagonizing the JA signaling pathway and by inhibition of auxin signaling [22,64]. However, SA and JA signaling pathways have also been reported to be synergistic [64-66]. Our results suggest that SA may also participate in mechanisms associated with resistance/ tolerance to $B$. cinerea since the content in SA was higher in infected green but mainly infected veraison Syrah berries comparing to Trincadeira. At this stage only Syrah exhibited mild symptoms due to infection. Previous studies suggest a role of SA in response to infection with $B$. cinerea $[67,68]$. In addition, other studies in tomato and Arabidopsis suggest an interaction between JA and SA in promoting resistance [24,69], though the function of SA in immune responses may vary among plant species [70,71]. Previously, azelaic acid was identified as a positive marker of infection of Trincadeira green (EL33) and veraison (EL35) grapes with B. cinerea [4]. This compound is involved in priming the accumulation of SA in response to pathogen infection in Arabidopsis [72]. This accumulation of SA was observed for green Trincadeira grapes but not for veraison grapes, highlighting the complex regulation of hormonal metabolism that occurs in response to infection at different stages of ripening. It may be that the pathogen activates the azelaic acid response, but the priming or another downstream process is suppressed or not recognized later during ripening and therefore systemic acquired resistance and the salicylic acid response is not activated as previously suggested [4]. Altogether, it is therefore tempting to speculate that different cultivars may have a different JA and SA balance also in response to necrotrophs and the associated immune response may be therefore distinct. Additionally, only at EL38 Syrah presented significant symptoms of infection and at this stage SA content is similar between the two cultivars.

In basal and in effector-triggered immunity, EDS1 and PAD4, promote SA accumulation. These direct partners are currently considered to act upstream of SA signaling [46,73]. Recently, an early function of EDS1/PAD4 signaling independent of generated SA has been described [74]. This may justify the significant increase in EDS1 and PAD4 expression in infected Trincadeira berries at EL32 without reaching higher content in SA than Syrah. Previously, constitutive levels of SA and constitutive expression of EDS1 in leaves were associated with resistance against a biotrophic pathogen causing powdery mildew in grapevine; the susceptible cultivar presented delayed EDS1 expression induced by the fungus $[75,76]$. Similar results were obtained in this study for EDS1 and PAD4 highlighting that some regulatory mechanisms of defense responses may be common to necrotrophic and biotrophic pathogens. On the other hand, EDS1/ PAD4 have been indicated as negative regulators of ethylene/jasmonic acid defense signaling [77], raising the question on whether the high increase in EDS1 and PAD4 expression in infected green Trincadeira berries may lead to impairment in defense associated with JA in this cultivar which is a crucial hormone in response to B. cinerea [71].

The role played by jasmonates in grape response against Botrytis cinerea has been previously referred [4,19]. Interestingly, in tomato transcriptional reprogramming of important JA-signaling components (e.g., MYC2) was not noticed during fruit infection [24]. However, MYC2 was up-regulated in infected Syrah grapes at EL35 and EL38 comparing with Trincadeira highlighting the importance of conducting studies in non-vegetative tissues and of comparing climacteric and nonclimacteric fruits. In addition, Syrah presented at EL32 and EL35 higher basal levels of expression of MYC2 than Trincadeira. Mutants of myc2 have been reported to present reduced resistance to $B$. cinerea [78] indicating that MYC2 may be a positive regulator of defense.

It should be also taken into account that pathogenic fungi can produce plant hormones and manipulate hormonal regulation of plant defense [79]. However, there is no direct evidence that fungal SA or JA is required for their virulence [80].

Regarding auxins, little is known about their role in plant resistance to necrotrophs. However, auxin signaling has been connected to innate immunity, the activation of the auxin pathway mediates pathogen-associated molecular patterns (PAMP)-triggered susceptibility, and auxin opposing regulation mediates PAMP-triggered immunity (reviewed by Naseem et al. [81]). It has also been suggested an interaction between 


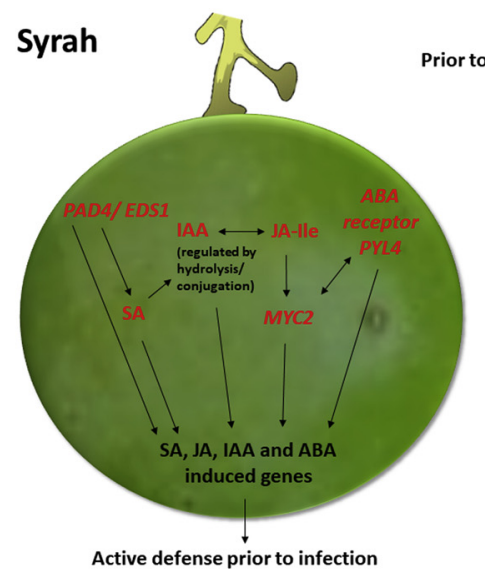

Active defense prior to infection BASAL IMMUNITY

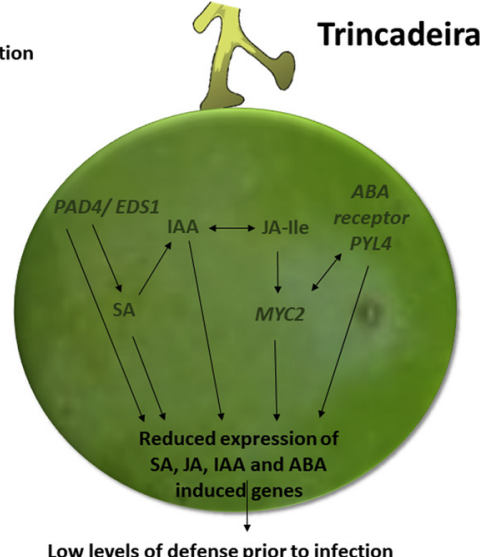

Low levels of defense prior to infection
Fig. 8. Hormonal metabolism in grapes from green clusters (EL32) before and after infection with $B$. cinerea and representing tolerant (Syrah) and susceptible (Trincadeira) genotypes. High levels are highlighted in red and low levels in green. Basal levels of hormones (IAA, SA and JA-Ile) in Syrah are putatively involved in a faster response to Botrytis cinerea. Jasmonates, ABA and SA signaling are also activated in Syrah grapes without infection. Trincadeira presents at green stage a more extensive reprogramming of hormonal metabolism upon infection (high increase in ABA, IAA, SA and JA-Ile content together with activation of jasmonate, IAA and SA signaling), but this is likely to result in delayed defense responses and inefficient defense. The kinetics of phytohormone biosynthesis and the timing and sequence of initiation of hormones' signaling during the interaction of fruit with $B$. cinerea may determine the outcome of hormones' interaction and successful defense (For interpretation of the references to colour in this figure legend, the reader is referred to the web version of this article).
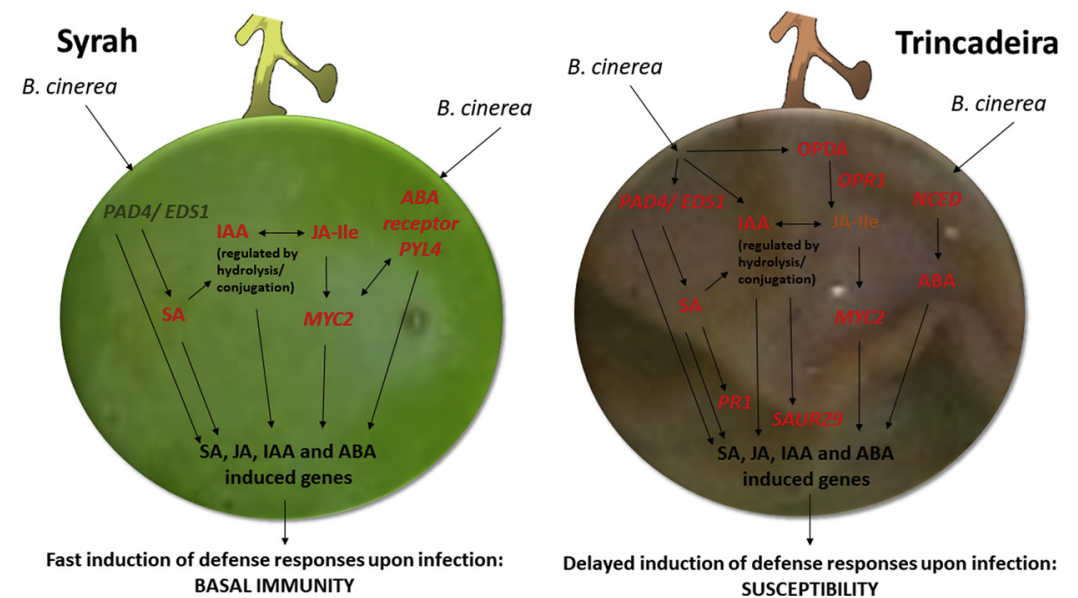

auxin and jasmonic acid in resistance to necrotrophs [29]. Considering the higher basal levels in IAA and JA-Ile in Syrah green berries it may be that these growth regulators are interacting in order to provide a fast response to pathogen attack leading to tolerance of this cultivar.

However, it has also been reported that several plant pathogens can directly synthesize auxin or induce plant auxin biosynthesis or alternatively modulate auxin signaling to stimulate susceptibility [27,82-84]. At EL32 infected Trincadeira berries presented increase in IAA content and up-regulation of auxin-responsive SAUR29 comparing to the control indicating that auxin signaling is activated upon the infection. Additionally, at EL35 infected Trincadeira berries presented higher content in IAA than infected Syrah berries and tendency for higher expression of AUX1. This gene was also up-regulated at EL38 in Syrah berries comparing to the control. At this stage, Syrah already presented significant symptoms of infection suggesting that the pathogen may influence auxin transport. Furthermore, the aux 1 mutant, which is defective in auxin influx, cannot present induced systemic resistance against $B$. cinerea [45]. Our analysis do not seem to corroborate this with increased expression of $A U X 1$ observed first for infected Trincadeira grapes at EL35 comparing to infected Syrah and an additional increase noted for Syrah at EL38 when they are both exhibiting heavy symptoms of infection. However, F. oxysporum, a hemibiotrophic pathogen, requires components of auxin signaling and transport for efficient plant colonization, suggesting that alteration of polar auxin transport may also confer increased pathogen resistance [27]. It should also be taken into account that $B$. cinerea can synthesize auxin [85], but the exact function of the pathogen-derived IAA during infection and in interaction with the plant host has not been elucidated.

Salicylic acid has been reported to induce the transcription of genes coding for IAA-conjugating enzyme GH3.5 that converts free IAA into inactive auxin [86]. In general, higher SA content reduce active IAA and repress auxin signaling leading to enhanced defense and reciprocally, SA-mediated defenses are attenuated by auxin (reviewed by Naseem et al. [81]). This was noticed at EL35 when comparing both cultivars. On the other hand, both cultivars at EL38 exhibited heavy symptoms of infection accompanied by lower levels of SA and increased expression of auxin-responsive SAUR29 which is in line with previous observations that increased auxin signaling leads to significant reduction in SA accumulation after pathogen infection [86,87].

ABA can also influence the outcome of plant-microbe interactions; in particular the effect of $\mathrm{ABA}$ in response against necrotrophic pathogens appears to be complex [71,88-90]. Abuqamar et al. [91] suggested a link between $\mathrm{ABA}$ and susceptibility towards $B$. cinerea in Arabidopsis. In tomato, increased expression of tomato NCED occurs during early infection of susceptible fruit suggesting that ABA synthesis leads to fruit susceptibility [24]. Our results suggest that ABA is involved in susceptibility of Trincadeira given the high increase in this growth regulator together with increased expression of NCED in infected grapes at EL32 comparing to control, though it can be also due to an acceleration of ripening and/ or dehydration promoted by the fungus. This was not noticed in Syrah at this stage; instead Syrah present higher basal expression of ABA receptor PYL4 RCAR10, so ABA signaling processes can eventually be connected to basal resistance in interaction with other growth regulators such as JA and SA [92,93]. In fact, negative and positive roles have been described for this hormone depending on the pathosystem, developmental stage of the plant, and/ or the environmental conditions in which the interaction occurs $[30,94,95]$. The results presented here suggest that it may also depend on intra-species genetic variation of hormone networks (Fig. 8). 


\section{Conclusions}

The combined analysis of the hormonal profile and targeted qPCR analysis of genes involved in hormonal metabolism during ripening and upon $B$. cinerea infection suggested new roles for SA, IAA and ABA in cultivar fruit specificities and in response to necrotrophic pathogens. High basal levels of SA and IAA at an early stage of ripening, together with activated SA and IAA metabolism and signaling (Fig. 8), and possibly in interaction with JA, seem to be important in providing a fast defense response leading to grape tolerance against $B$. cinerea.

The results indicate that the role of plant hormones in promoting fruit resistance or susceptibility is extremely complex depending not only on the relative content of the hormones, but also on the timing of the synthesis and perception of the hormones. Additionally, other factors may be important as well, namely the competence of the host tissue to respond to active hormones, the localization of the response, the pathogen lifestyle, including its own production of hormones [24,61]. Moreover, the balance and interaction among hormones may be crucial in providing either resistance or susceptibility; two genetic backgrounds in the same plant species may present different hormone signaling requirements for resistance [28] as indicated here. Further studies on inter- and intraspecies genetic variation of hormone networks may validate the importance of basal hormonal levels in resistance/ tolerance as suggested here. These might provide insights for exogenous treatments with hormones and possible strategies of manipulation using genome-editing technologies. In grapevine, the limitation will be the optimization of transgenesis' protocols for different cultivars enabling functional gene characterization in grapes [96]. Additionally, further hormonomics and RNA sequencing applied to the specific study of cells and tissues will elucidate unknown functions of plant hormones in fruit growth, development and quality as well as in response against pathogens.

\section{Conflict of interest}

The authors declare that they have no conflict of interest.

\section{Author contributions}

J.C., M. A-Trapp, D.P., F.S. and AMF carried out the experiments; P.R and C.R. performed the infections. AMF designed the study and wrote the manuscript with input from A.M.

\section{Acknowledgments}

This work was supported by the Portuguese Fundação para a Ciência e Tecnologia (FCT) [grant numbers UID/Multi/04046/2013, FCT Investigator IF/00169/2015, Fellowships PD/BD/114385/2016 and PB/BD/130976/2017]. Ana M. Fortes and Marilia Almeida-Trapp gratefully acknowledge financial support by the Innovation Prize CNOIV 2016 and by a Capes-Humboldt Research Fellowship, respectively.

\section{Appendix A. Supplementary data}

Supplementary material related to this article can be found, in the online version, at doi:https://doi.org/10.1016/j.plantsci.2019.01.024.

\section{References}

1] A.M. Fortes, R.T. Teixeira, P. Agudelo-Romero, Complex interplay of hormona signals during grape berry ripening, Molecules 20 (2015) 9326-9343, https://doi. org/10.3390/molecules20059326.

[2] N. Alkan, A.M. Fortes, Insights into molecular and metabolic events associated with fruit response to post-harvest fungal pathogens, Front. Plant Sci. 6 (2015) 1-14, https://doi.org/10.3389/fpls.2015.00889.

[3] P. Agudelo-Romero, C. Bortolloti, M.S. Pais, A.F. Tiburcio, A.M. Fortes, Study of polyamines during grape ripening indicate an important role of polyamine catabolism, Plant Physiol. Biochem. 67 (2013) 105-119, https://doi.org/10.1016/j. plaphy.2013.02.024.

[4] P. Agudelo-Romero, A. Erban, C. Rego, P. Carbonell-Bejerano, T. Nascimento, L. Sousa, J.M. Martínez-Zapater, J. Kopka, A.M. Fortes, Transcriptome and metabolome reprogramming in Vitis vinifera cv. Trincadeira berries upon infection with Botrytis cinerea, J. Exp. Bot. 66 (2015) 1769-1785, https://doi.org/10.1093/jxb/ eru517.

[5] C. Chervin, A. El-Kereamy, J.P. Roustan, A. Latché, J. Lamon, M. Bouzayen, Ethylene seems required for the berry development and ripening in grape, a nonclimacteric fruit, Plant Sci. 167 (2004) 1301-1305, https://doi.org/10.1016/j. plantsci.2004.06.026.

[6] N. Kuhn, L. Guan, Z.W. Dai, B.H. Wu, V. Lauvergeat, E. Gomès, S.H. Li, F. Godoy, P. Arce-Johnson, S. Delrot, Berry ripening: recently heard through the grapevine, J. Exp. Bot. 65 (2014) 4543-4559, https://doi.org/10.1093/jxb/ert395.

[7] C. Davies, C. Böttcher, Hormonal control of grape berry ripening, Grapevine Mol. Physiol. Biotechnol. Springer, Netherlands, Dordrecht, 2009, pp. 229-261, https:// doi.org/10.1007/978-90-481-2305-6_9.

[8] S. Lacampagne, S. Gagné, L. Gény, Involvement of abscisic acid in controlling the proanthocyanidin biosynthesis pathway in grape skin: new elements regarding the regulation of tannin composition and leucoanthocyanidin reductase (LAR) and anthocyanidin reductase (ANR) activities and expres, J. Plant Growth Regul. 29 (2010) 81-90, https://doi.org/10.1007/s00344-009-9115-6.

[9] L. Villalobos-González, A. Peña-Neira, F. Ibáñez, C. Pastenes, Long-term effects of abscisic acid (ABA) on the grape berry phenylpropanoid pathway: gene expression and metabolite content, Plant Physiol. Biochem. 105 (2016) 213-223, https://doi. org/10.1016/j.plaphy.2016.04.012.

[10] P. Leng, B. Yuan, Y. Guo, The role of abscisic acid in fruit ripening and responses to abiotic stress, J. Exp. Bot. 65 (2014) 4577-4588, https://doi.org/10.1093/jxb/ eru204.

[11] R. Kumar, A. Khurana, A.K. Sharma, Role of plant hormones and their interplay in development and ripening of fleshy fruits, J. Exp. Bot. 65 (2014) 4561-4575, https://doi.org/10.1093/jxb/eru277.

[12] C. Böttcher, P.K. Boss, C. Davies, Acyl substrate preferences of an IAA-amido synthetase account for variations in grape (Vitis vinifera L.) berry ripening caused by different auxinic compounds indicating the importance of auxin conjugation in plant development, J. Exp. Bot. 62 (2011) 4267-4280, https://doi.org/10.1093/ jxb/err134.

[13] C. Davies, P.K. Boss, S.P. Robinson, Treatment of crape berries, a nonclimacteric fruit with a synthetic auxin, retards ripening and alters the expression of developmentally regulated genes, Plant Physiol. 11 (1997), https://doi.org/10.1104/PP. 115.3.1155 55-1.

[14] C. Böttcher, R.A. Keyzers, P.K. Boss, C. Davies, Sequestration of auxin by the indole3-acetic acid-amido synthetase GH3-1 in grape berry (Vitis vinifera L.) and the proposed role of auxin conjugation during ripening, J. Exp. Bot. 61 (2010) 3615-3625, https://doi.org/10.1093/jxb/erq174.

[15] F. Ziliotto, M. Corso, F.M. Rizzini, A. Rasori, A. Botton, C. Bonghi, Grape berry ripening delay induced by a pre-véraison NAA treatment is paralleled by a shift in the expression pattern of auxin- and ethylene-related genes, BMC Plant Biol. 12 (2012) 185, https://doi.org/10.1186/1471-2229-12-185.

[16] P. Agudelo-Romero, A. Erban, L. Sousa, M.S. Pais, J. Kopka, A.M. Fortes, Search for transcriptional and metabolic markers of grape pre-ripening and ripening and insights into specific aroma development in three portuguese cultivars, PLoS One 8 (2013), https://doi.org/10.1371/journal.pone.0060422.

[17] D.A. Breitel, L. Chappell-Maor, S. Meir, I. Panizel, C.P. Puig, Y. Hao, T. Yifhar, H. Yasuor, M. Zouine, M. Bouzayen, A. Granell Richart, I. Rogachev, A. Aharoni, AUXIN RESPONSE FACTOR 2 intersects hormonal signals in the regulation of tomato fruit ripening, PLoS Genet. 12 (2016) e1005903, https://doi.org/10.1371/ journal.pgen.1005903.

[18] A.M. Fortes, P. Agudelo-Romero, M.S. Silva, K. Ali, L. Sousa, F. Maltese, Y.H. Choi, J. Grimplet, J.M. Martinez-Zapater, R. Verpoorte, M.S. Pais, Transcript and metabolite analysis in Trincadeira cultivar reveals novel information regarding the dynamics of grape ripening, BMC Plant Biol. 11 (2011) 1-34, https://doi.org/10. 1186/1471-2229-11-149.

[19] H. Jia, C. Zhang, T. Pervaiz, P. Zhao, Z. Liu, B. Wang, C. Wang, L. Zhang, J. Fang, J. Qian, Jasmonic acid involves in grape fruit ripening and resistant against Botrytis cinerea, Funct. Integr. Genom. 16 (2016) 79-94, https://doi.org/10.1007/s10142015-0468-6.

[20] D.R. Rudell, J.P. Mattheis, X. Fan, J.K. Fellman, Methyl jasmonate enhances anthocyanin accumulation and modifies production of phenolics and pigments in "Fuji" apples, J. Am. Soc. Hortic. Sci. 127 (2002) 435-441, https://doi.org/10. 1104/pp.010843.

[21] W. Wang, M. Khalil-Ur-Rehman, J. Feng, J.M. Tao, The effect of pre-harvest methyl jasmonate treatment on the selected volatile compounds and endogenous hormones contends in the pulp of grape berries, J. Plant Biochem. Physiol. 05 (2017), https:// doi.org/10.4172/2329-9029.1000192.

[22] J. Glazebrook, Contrasting mechanisms of defense against biotrophic and necrotrophic pathogens, Annu. Rev. Phytopathol. 43 (2005) 205-227, https://doi.org/ 10.1146/annurev.phyto.43.040204.135923.

[23] E. Smirnova, V. Marquis, L. Poirier, Y. Aubert, J. Zumsteg, R. Ménard, L. Miesch, T. Heitz, Jasmonic acid oxidase 2 hydroxylates jasmonic acid and represses basal defense and resistance responses against Botrytis cinerea infection, Mol. Plant 10 (2017) 1159-1173, https://doi.org/10.1016/j.molp.2017.07.010.

[24] B. Blanco-Ulate, E. Vincenti, A.L.T. Powell, D. Cantu, Tomato transcriptome and mutant analyses suggest a role for plant stress hormones in the interaction between fruit and Botrytis cinerea, Front. Plant Sci. 4 (2013) 142, https://doi.org/10.3389/ 
fpls.2013.00142.

[25] N. Alkan, R. Fluhr, D. Prusky, Ammonium secretion during Colletotrichum coccodes infection modulates salicylic and jasmonic acid pathways of ripe and unripe tomato fruit, Mol. Plant Microbe Interact. 25 (2012) 85-96, https://doi.org/10.1094/ MPMI-01-11-0020.

[26] P.A. Brading, K.E. Hammond-Kosack, A. Parr, J.D.G. Jones, Salicylic acid is not required for Cf-2- and Cf-9-dependent resistance of tomato to Cladosporium fulvum, Plant J. 23 (2000) 305-318, https://doi.org/10.1046/j.1365-313X.2000.00778.x.

[27] B.N. Kidd, N.Y. Kadoo, B. Dombrecht, M. Tekeoglu, D.M. Gardiner, L.F. Thatcher, E.A.B. Aitken, P.M. Schenk, J.M. Manners, K. Kazan, Auxin signaling and transport promote susceptibility to the root-infecting fungal pathogen Fusarium oxysporum in Arabidopsis, Mol. Plant Microbe Interact. 24 (2011) 733-748, https://doi.org/10. 1094/MPMI-08-10-0194.

[28] M.L. Berens, H.M. Berry, A. Mine, C.T. Argueso, K. Tsuda, Evolution of hormone signaling networks in plant defense, Annu. Rev. Phytopathol. 55 (2017), https:// doi.org/10.1146/annurev-phyto-080516-035544 annurev-phyto-080516-035544.

[29] L. Qi, J. Yan, Y. Li, H. Jiang, J. Sun, Q. Chen, H. Li, J. Chu, C. Yan, X. Sun, Y. Yu, C. Li, C. Li, Arabidopsis thaliana plants differentially modulate auxin biosynthesis and transport during defense responses to the necrotrophic pathogen Alternaria brassicicola, New Phytol. 195 (2012) 872-882, https://doi.org/10.1111/j.14698137.2012.04208.x.

[30] A. Robert-Seilaniantz, M. Grant, J.D.G. Jones, Hormone crosstalk in plant disease and defense: more than just jasmonate-salicylate antagonism, Annu. Rev. Phytopathol. 49 (2011) 317-343, https://doi.org/10.1146/annurev-phyto-073009114447.

[31] A. Sánchez-Vallet, G. López, B. Ramos, M. Delgado-Cerezo, M.-P. Riviere, F. Llorente, P.V. Fernández, E. Miedes, J.M. Estevez, M. Grant, A. Molina, Disruption of abscisic acid signaling constitutively activates Arabidopsis resistance to the necrotrophic fungus Plectosphaerella cucumerina, Plant Physiol. 160 (2012) 2109-2124, https://doi.org/10.1104/pp.112.200154.

[32] V. Siewers, J. Smedsgaard, P. Tudzynski, The P450 monooxygenase BcABA1 is essential for abscisic acid biosynthesis in Botrytis cinerea, Appl. Environ. Microbiol. 70 (2004) 3868-38676, https://doi.org/10.1128/AEM.70.7.3868.

[33] C. Paňitrur-De La Fuente, H. Valdés-Gómez, J. Roudet, C. Acevedo-Opazo, N. Verdugo-Vásquez, M. Araya-Alman, M. Lolas, Y. Moreno, M. Fermaud, Classification of winegrape cultivars in Chile and France according to their susceptibility to Botrytis cinerea related to fruit maturity, Aust. J. Grape Wine Res. 24 (2017) 145-157, https://doi.org/10.1111/ajgw.12315.

[34] B.G. COOMBE, Growth stages of the grapevine: adoption of a system for identifying grapevine growth stages, Aust. J. Grape Wine Res. 1 (1995) 104-110, https://doi. org/10.1111/j.1755-0238.1995.tb00086.x.

[35] P. Agudelo-Romero, K. Ali, Y.H. Choi, L. Sousa, R. Verpoorte, A.F. Tiburcio, A.M. Fortes, Perturbation of polyamine catabolism affects grape ripening of Vitis vinifera cv. Trincadeira, Plant Physiol. Biochem. 74 (2014) 141-155, https://doi. org/10.1016/j.plaphy.2013.11.002.

[36] M.A. Lodhi, G.-N. Ye, N.F. Weeden, B.I. Reisch, A simple and efficient method for DNA extraction from grapevine cultivars andVitis species, Plant Mol. Biol. Rep. 12 (1994) 6-13, https://doi.org/10.1007/BF02668658.

[37] M. Almeida Trapp, G.D. De Souza, E. Rodrigues-Filho, W. Boland, A. Mithöfer, Validated method for phytohormone quantification in plants, Front. Plant Sci. 5 (2014) 417, https://doi.org/10.3389/fpls.2014.00417.

[38] M. Massonnet, M. Fasoli, G.B. Tornielli, M. Altieri, M. Sandri, P. Zuccolotto, P. Paci, M. Gardiman, S. Zenoni, M. Pezzotti, Ripening transcriptomic program in red and white grapevine varieties correlates with berry skin anthocyanin accumulation, Plant Physiol. 174 (2017) 2376-2396, https://doi.org/10.1104/pp.17.00311.

[39] A. Calonnec, P. Cartolar, C. Poupot, D. Dubourdieu, P. Darriet, Effects of Uncinula necator on the yield and quality of grapes (Vitis vinifera) and wine, Plant Pathol. 53 (2004) 434-445, https://doi.org/10.1111/j.1365-3059.2004.01016.x.

[40] I. Ky, B. Lorrain, M. Jourdes, G. Pasquier, M. Fermaud, L. Gény, P. Rey, B. Doneche, P.L. Teissedre, Assessment of grey mould (Botrytis cinerea) impact on phenolic and sensory quality of Bordeaux grapes, musts and wines for two consecutive vintages, Aust. J. Grape Wine Res. 18 (2012) 215-226, https://doi.org/10.1111/j.17550238.2012.00191.x.

[41] S. Fonseca, J.M. Chico, R. Solano, The jasmonate pathway: the ligand, the receptor and the core signalling module, Curr. Opin. Plant Biol. 12 (2009) 539-547, https:// doi.org/10.1016/j.pbi.2009.07.013.

[42] A. Chini, S. Fonseca, G. Fernández, B. Adie, J.M. Chico, O. Lorenzo, G. GarcíaCasado, I. López-Vidriero, F.M. Lozano, M.R. Ponce, J.L. Micol, R. Solano, The JAZ family of repressors is the missing link in jasmonate signalling, Nature 448 (2007) 666-671, https://doi.org/10.1038/nature06006.

[43] J. Fu, S. Wang, Insights into auxin signaling in plant-pathogen interactions, Front. Plant Sci. 2 (2011), https://doi.org/10.3389/fpls.2011.00074.

[44] S. Kant, Y.-M. Bi, T. Zhu, S.J. Rothstein, SAUR39, a small auxin-up RNA gene, acts as a negative regulator of auxin synthesis and transport in rice, Plant Physiol. 151 (2009) 691-701, https://doi.org/10.1104/pp.109.143875.

[45] N. Korolev, D. Rav David, Y. Elad, The role of phytohormones in basal resistance and Trichoderma-induced systemic resistance to Botrytis cinerea in Arabidopsis thaliana, BioControl 53 (2008) 667-683, https://doi.org/10.1007/s10526-0079103-3.

[46] M. Wiermer, B.J. Feys, J.E. Parker, Plant immunity: the EDS1 regulatory node, Curr. Opin. Plant Biol. 8 (2005) 383-389, https://doi.org/10.1016/j.pbi.2005.05.010.

[47] F. Aleman, J. Yazaki, M. Lee, Y. Takahashi, A.Y. Kim, Z. Li, T. Kinoshita, J.R. Ecker, J.I. Schroeder, An ABA-increased interaction of the PYL6 ABA receptor with MYC2 transcription factor: a putative link of ABA and JA signaling, Sci. Rep. 6 (2016) 28941, https://doi.org/10.1038/srep28941.

[48] K. Shiratake, M. Suzuki, Omics studies of citrus, grape and rosaceae fruit trees,
Breed. Sci. 138 (2016) 122-138, https://doi.org/10.1270/jsbbs.66.122.

[49] A. Oikawa, T. Otsuka, R. Nakabayashi, Y. Jikumaru, K. Isuzugawa, H. Murayama, K. Saito, K. Shiratake, Metabolic profiling of developing pear fruits reveals dynamic variation in primary and secondary metabolites, including plant hormones, PLoS One 10 (2015) e0131408, https://doi.org/10.1371/journal.pone.0131408.

[50] S. Wheeler, B. Loveys, C. Ford, C. Davies, The relationship between the expression of abscisic acid biosynthesis genes, accumulation of abscisic acid and the promotion of Vitis vinifera L. berry ripening by abscisic acid, Aust. J. Grape Wine Res. 15 (2009) 195-204, https://doi.org/10.1111/j.1755-0238.2008.00045.x.

[51] S. Pilati, G. Bagagli, P. Sonego, M. Moretto, D. Brazzale, G. Castorina, L. Simoni, C. Tonelli, G. Guella, K. Engelen, M. Galbiati, C. Moser, Abscisic acid is a major regulator of grape berry ripening onset: new insights into ABA signaling network, Front. Plant Sci. 8 (2017) 1-16, https://doi.org/10.3389/fpls.2017.01093.

[52] S.D. Castellarin, G.A. Gambetta, H. Wada, M.N. Krasnow, G.R. Cramer, E. Peterlunger, K.A. Shackel, M.A. Matthews, Characterization of major ripening events during softening in grape: turgor, sugar accumulation, abscisic acid metabolism, colour development, and their relationship with growth, J. Exp. Bot. 67 (2016) 709-722, https://doi.org/10.1093/jxb/erv483.

[53] S. Rattanakon, R. Ghan, G.A. Gambetta, L.G. Deluc, K.A. Schlauch, G.R. Cramer, Abscisic acid transcriptomic signaling varies with grapevine organ, BMC Plant Biol. 16 (2016) 72, https://doi.org/10.1186/s12870-016-0763-y.

[54] C.M. Cantín, M.W. Fidelibus, C.H. Crisosto, Application of abscisic acid (ABA) at veraison advanced red color development and maintained postharvest quality of 'Crimson Seedless' grapes, Postharvest Biol. Technol. 46 (2007) 237-241, https:// doi.org/10.1016/j.postharvbio.2007.05.017.

[55] A.K. Spartz, S.H. Lee, J.P. Wenger, N. Gonzalez, H. Itoh, D. Inzé, W.A. Peer, A.S. Murphy, P.J. Overvoorde, W.M. Gray, The SAUR19 subfamily of SMALL AUXIN UP RNA genes promote cell expansion, Plant J. 70 (2012) 978-990, https://doi. org/10.1111/j.1365-313X.2012.04946.x.

[56] C. Böttcher, C.A. Burbidge, P.K. Boss, C. Davies, Interactions between ethylene and auxin are crucial to the control of grape (Vitis vinifera L.) berry ripening, BMC Plant Biol. 13 (2013) 222, https://doi.org/10.1186/1471-2229-13-222.

[57] M. Manohar, D. Wang, P.M. Manosalva, H.W. Choi, E. Kombrink, D.F. Klessig, Members of the abscisic acid co-receptor PP2C protein family mediate salicylic acidabscisic acid crosstalk, Plant Direct 1 (2017) e00020, https://doi.org/10.1002/ pld3.20.

[58] E. Kraeva, C. Andary, A. Carbonneau, A. Deloire, Salicylic acid treatment of grape berries retards ripening, Vitis 37 (1998) 143-144.

[59] M.K. Srivastava, U.N. Dwivedi, Delayed ripening of banana fruit by salicylic acid, Plant Sci. 158 (2000) 87-96, https://doi.org/10.1016/S0168-9452(00)00304-6.

[60] M. Szechyńska-Hebda, W. Czarnocka, M. Hebda, S. Karpiński, PAD4, LSD1 and EDS1 regulate drought tolerance, plant biomass production, and cell wall properties, Plant Cell Rep. 35 (2016) 527-539, https://doi.org/10.1007/s00299-0151901-y.

[61] C.M.J. Pieterse, A. Leon-Reyes, S. Van der Ent, S.C.M. Van Wees, Networking by small-molecule hormones in plant immunity, Nat. Chem. Biol. 5 (2009) 308-316, https://doi.org/10.1038/nchembio.164.

[62] W.E. Durrant, X. Dong, Systemic acquired resistance, Annu. Rev. Phytopathol. 42 (2004) 185-209, https://doi.org/10.1146/annurev.phyto.42.040803.140421.

[63] A.C. Vlot, D.A. Dempsey, D.F. Klessig, Salicylic acid, a multifaceted hormone to combat disease, Annu. Rev. Phytopathol. 47 (2009) 177-206, https://doi.org/10. 1146/annurev.phyto.050908.135202.

[64] A. Koornneef, A. Leon-Reyes, T. Ritsema, A. Verhage, F.C. Den Otter, L.C. Van Loon, C.M.J. Pieterse, Kinetics of salicylate-mediated suppression of jasmonate signaling reveal a role for redox modulation, Plant Physiol. 147 (2008) 1358-1368, https:// doi.org/10.1104/pp.108.121392.

[65] L.A.J. Mur, The outcomes of concentration-specific interactions between salicylate and jasmonate signaling include synergy, antagonism, and oxidative stress leading to cell death, Plant Physiol. 140 (2005) 249-262, https://doi.org/10.1104/pp.105. 072348.

[66] M. El Oirdi, T.A. El Rahman, L. Rigano, A. El Hadrami, M.C. Rodriguez, F. Daayf, A. Vojnov, K. Bouarab, Botrytis cinerea manipulates the antagonistic effects between immune pathways to promote disease development in tomato, Plant Cell 23 (2011) 2405-2421, https://doi.org/10.1105/tpc.111.083394.

[67] I. Ponce De León, E.A. Schmelz, C. Gaggero, A. Castro, A. Álvarez, M. Montesano, Physcomitrella patens activates reinforcement of the cell wall, programmed cell death and accumulation of evolutionary conserved defence signals, such as salicylic acid and 12-oxo-phytodienoic acid, but not jasmonic acid, upon Botrytis cinerea infection, Mol. Plant Pathol. 13 (2012) 960-974, https://doi.org/10.1111/j.1364. 3703.2012.00806.x.

[68] C. Angulo, M. de la O. Leyva, I. Finiti, J. López-Cruz, E. Fernández-Crespo, P. García-Agustín, C. González-Bosch, Role of dioxygenase $\alpha$-DOX2 and SA in basal response and in hexanoic acid-induced resistance of tomato (Solanum lycopersicum) plants against Botrytis cinerea, J. Plant Physiol. 175 (2015) 163-173, https://doi.org/10.1016/j.jplph.2014.11.004.

[69] S. Lemarié, A. Robert-Seilaniantz, C. Lariagon, J. Lemoine, N. Marnet, M. Jubault, M.J. Manzanares-Dauleux, A. Gravot, Both the jasmonic acid and the salicylic acid pathways contribute to resistance to the biotrophic clubroot agent Plasmodiophora brassicae in Arabidopsis, Plant Cell Physiol. (2015) pcv127, https://doi.org/10. 1093/pcp/pcv127.

[70] D. de Vleesschauwer, S. Seifi, O. Filipe, A. Haeck, S. Nguyen Huu, K. Demeestere, M.M. Höfte, The DELLA protein SLR1 integrates and amplifies salicylic acid- and jasmonic acid-dependent innate immunity in rice, Plant Physiol. (2016), https:// doi.org/10.1104/pp.15.01515 pp. 01515.2015.

[71] S. AbuQamar, K. Moustafa, L.S.P. Tran, Mechanisms and strategies of plant defense against Botrytis cinerea, Crit. Rev. Biotechnol. 37 (2017) 262-274, https://doi.org/ 
10.1080/07388551.2016.1271767.

[72] H.W. Jung, T.J. Tschaplinski, L. Wang, J. Glazebrook, J.T. Greenberg, Priming in systemic plant immunity, Science 324 (2009) 89-91, https://doi.org/10.1126/ science.1170025 (80-.).

[73] S. Wagner, J. Stuttmann, S. Rietz, R. Guerois, E. Brunstein, J. Bautor, K. Niefind, J.E. Parker, Structural basis for signaling by exclusive EDS1 heteromeric complexes with SAG101 or PAD4 in plant innate immunity, Cell Host Microbe 14 (2013) 619-630, https://doi.org/10.1016/j.chom.2013.11.006.

[74] H. Cui, E. Gobbato, B. Kracher, J. Qiu, J. Bautor, J.E. Parker, A core function of EDS1 with PAD4 is to protect the salicylic acid defense sector in Arabidopsis immunity, New Phytol. 213 (2017) 1802-1817, https://doi.org/10.1111/nph.14302.

[75] R.W.M. Fung, M. Gonzalo, C. Fekete, L.G. Kovacs, Y. He, E. Marsh, L.M. McIntyre, D.P. Schachtman, W. Qiu, Powdery mildew induces defense-oriented reprogramming of the transcriptome in a susceptible but not in a resistant grapevine, Plant Physiol. 146 (2008) 236-249, https://doi.org/10.1104/pp.107.108712.

[76] F. Gao, R. Dai, S.M. Pike, W. Qiu, W. Gassmann, Functions of EDS1-like and PAD4 genes in grapevine defenses against powdery mildew, Plant Mol. Biol. 86 (2014) 381-393, https://doi.org/10.1007/s11103-014-0235-4.

[77] P. Brodersen, M. Petersen, H. Bjørn Nielsen, S. Zhu, M.-A. Newman, K.M. Shokat, S. Rietz, J. Parker, J. Mundy, Arabidopsis MAP kinase 4 regulates salicylic acid- and jasmonic acid/ethylene-dependent responses via EDS1 and PAD4, Plant J. 47 (2006) 532-546, https://doi.org/10.1111/j.1365-313X.2006.02806.x.

[78] O. Lorenzo, JASMONATE-INSENSITIVE1 encodes a MYC transcription factor essential to discriminate between different jasmonate-regulated defense responses in Arabidopsis, Plant Cell Online 16 (2004) 1938-1950, https://doi.org/10.1105/tpc. 022319.

[79] R.N. Patkar, N.I. Naqvi, Fungal manipulation of hormone-regulated plant defense, PLoS Pathog. 13 (2017) 10-14, https://doi.org/10.1371/journal.ppat.1006334.

[80] E. Chanclud, J.-B. Morel, Plant hormones: a fungal point of view, Mol. Plant Pathol. 17 (2016) 1289-1297, https://doi.org/10.1111/mpp.12393.

[81] M. Naseem, M. Kaltdorf, T. Dandekar, The nexus between growth and defence signalling: auxin and cytokinin modulate plant immune response pathways, J. Exp. Bot. 66 (2015) 4885-4896, https://doi.org/10.1093/jxb/erv297.

[82] E. Glickmann, L. Gardan, S. Jacquet, S. Hussain, M. Elasri, A. Petit, Y. Dessaux, Auxin production is a common feature of most pathovars of Pseudomonas syringae, Mol. Plant Microbe Interact. 11 (1998) 156-162, https://doi.org/10.1094/MPMI. 1998.11.2.156.

[83] Z. Chen, J.L. Agnew, J.D. Cohen, P. He, L. Shan, J. Sheen, B.N. Kunkel, Pseudomonas syringae type III effector AvrRpt2 alters Arabidopsis thaliana auxin physiology, Proc. Natl. Acad. Sci. U. S. A. 104 (2007) 20131-20136, https://doi. org/10.1073/pnas.0704901104.

[84] K. Kazan, R. Lyons, Intervention of phytohormone pathways by pathogen effectors, Plant Cell 26 (2014) 2285-2309, https://doi.org/10.1105/tpc.114.125419.
[85] A. Sharon, Y. Elad, R. Barakat, P. Tudzynski, Phytohormones in botrytis-plant interactions, Botrytis Biol. Pathol. Control, Springer, Netherlands, Dordrecht, 2007, pp. 163-179, https://doi.org/10.1007/978-1-4020-2626-3_10.

[86] D. Wang, K. Pajerowska-Mukhtar, A.H. Culler, X. Dong, Salicylic acid inhibits pathogen growth in plants through repression of the auxin signaling pathway, Curr. Biol. 17 (2007) 1784-1790, https://doi.org/10.1016/j.cub.2007.09.025.

[87] A. Robert-Seilaniantz, D. MacLean, Y. Jikumaru, L. Hill, S. Yamaguchi, Y. Kamiya, J.D.G. Jones, The microRNA miR393 re-directs secondary metabolite biosynthesis away from camalexin and towards glucosinolates, Plant J. 67 (2011) 218-231, https://doi.org/10.1111/j.1365-313X.2011.04591.x.

[88] J. Ton, B. Mauch-Mani, Beta-amino-butyric acid-induced resistance against necrotrophic pathogens is based on ABA-dependent priming for callose, Plant J. 38 (2004) 119-130, https://doi.org/10.1111/j.1365-313X.2004.02028.x.

[89] B. Asselbergh, K. Curvers, S.C. Franca, K. Audenaert, M. Vuylsteke, F. Van Breusegem, M. Hofte, Resistance to Botrytis cinerea in sitiens, an abscisic acid-deficient tomato mutant, involves timely production of hydrogen peroxide and cell wall modifications in the epidermis, Plant Physiol. 144 (2007) 1863-1877, https:// doi.org/10.1104/pp.107.099226.

[90] K. Curvers, H. Seifi, G. Mouille, R. de Rycke, B. Asselbergh, A. Van Hecke, D. Vanderschaeghe, H. Höfte, N. Callewaert, F. Van Breusegem, M. Höfte, Abscisic acid deficiency causes changes in cuticle permeability and pectin composition that influence tomato resistance to Botrytis cinerea, Plant Physiol. 154 (2010) 847-860, https://doi.org/10.1104/pp.110.158972.

[91] S. Abuqamar, S. Ajeb, A. Sham, M.R. Enan, R. Iratni, A mutation in the expansinlike A2 gene enhances resistance to necrotrophic fungi and hypersensitivity to abiotic stress in Arabidopsis thaliana, Mol. Plant Pathol. 14 (2013) 813-827, https://doi.org/10.1111/mpp.12049.

[92] B.A.T. Adie, J. Pérez-Pérez, M.M. Pérez-Pérez, M. Godoy, J.-J. Sánchez-Serrano, E.A. Schmelz, R. Solano, ABA is an essential signal for plant resistance to pathogen affecting JA biosynthesis and the activation of defenses in Arabidopsis, Plant Cell 19 (2007) 1665-1681, https://doi.org/10.1105/tpc.106.048041.

[93] P.J. Seo, C.-M. Park, MYB96-mediated abscisic acid signals induce pathogen resistance response by promoting salicylic acid biosynthesis in Arabidopsis, New Phytol. 186 (2010) 471-483, https://doi.org/10.1111/j.1469-8137.2010.03183.x.

[94] B. Mauch-Mani, F. Mauch, The role of abscisic acid in plant-pathogen interactions, Curr. Opin. Plant Biol. 8 (2005) 409-414, https://doi.org/10.1016/j.pbi.2005.05. 015.

[95] J. Ton, V. Flors, B. Mauch-Mani, The multifaceted role of ABA in disease resistance, Trends Plant Sci. 14 (2009) 310-317, https://doi.org/10.1016/j.tplants.2009.03. 006.

[96] A.M. Fortes, P. Gallusci, Plant stress responses and phenotypic plasticity in the epigenomics era: perspectives on the grapevine scenario, a model for perennial crop plants, Front. Plant Sci. 08 (2017) 1-9, https://doi.org/10.3389/fpls.2017.00082. 